\title{
The Role of eParticipation in the Expansion of Individual Capabilities
}

\author{
Marie Anne Macadar ${ }^{\bowtie 1[0000-0003-2744-5352]}$, Gabriela Viale Pereira ${ }^{20000-0002-7602-3052]}$ and \\ Fernando Bichara Pinto ${ }^{1}$ \\ ${ }^{1}$ Federal University of Rio de Janeiro, Rua Pascoal Lemme, 355 - 21941-918 - Brazil \\ marie.macadar@coppead.ufrj.br and fernando.pinto@coppead.ufrj.br \\ ${ }^{2}$ Dr.-Karl-Dorrek-Straße 30 | 3500 Krems a. d. Donau | Austria \\ gabriela.viale-pereira@donau-uni.ac.at
}

\begin{abstract}
This article seeks to understand how eParticipation can boost individual capabilities in an ICT4D context. The analysis has regard eParticipation as a mechanism for expanding capabilities since it increases the democratic and participatory involvement of individuals in society. To this end, we examined the eParticipation field according to Sæbø et al. [20] and Medaglia [13], combining the capability approach from Sen's [23] and Nussbaum's [17] perspectives. Although the literature recognized that the capability approach is particularly difficult to operationalize in practice, we discovered some mechanisms in the eParticipation literature to support our analysis. However, despite its apparent benefits, eParticipation can indirectly contribute toward increasing inequalities among people since it is not available to all. We believe that recognition of the inequalities generated by the digital divide and the subsequent decrease in eParticipation could lead to a better understanding of the ICT4D context and assist in public policy-making.
\end{abstract}

Keywords:eParticipation, Capability Approach (CA), Information and Communication Technology for Development (ICT4D)

\section{Introduction}

Medaglia [13] offers an eParticipation definition that faces this category of electronic government as "[...] issues of enabling opportunities for consultation and dialogue be-tween government and citizens by using a range of ICT tools" [13 p.346]. However, if eParticipation can be a way to foster citizen awareness and participation in public policy decision-making, it can increase inequalities between people with and without ICT access and skills, what jeopardizes the eParticipation philosophy itself ${ }^{1}$.

Considering eParticipation in terms of citizens' capabilities development, it is possible to assess the impact of ICT beyond superficial levels of access and use or its economic benefits [27],[14]. Instead of focusing solely on technological determinants,

${ }^{1}$ Helbig et al. [9] highlight that traditional digital divide factors, such as infrastructure and information availability, must be carefully considered in eParticipation initiatives. Contextual factors also play an important role in this double-edged nature of eParticipation. 
we adopt Amartya Sen's capability approach (CA) in the ICT for development (ICT4D) context to study eParticipation. This approach to human well-being emphasizesthe importance of freedom of choice as individual empowerment. In Sen's view, the term 'capability' refers to environmental opportunities and the individual abilities a person needs in order to live the life he or she wants [23].

Although Madon's work from 2004 employed CA as a theoretical resource to understand how effectively people benefit from the use of ICT applications and access, is still missing the look at what people can or cannot do with the ICT applications provided [27] ICT use has been supported by the principles of CA in ICT4D research and theoretical exploration regarding the application of CA to ICT and human development [27]. However, Zheng [27] claims that CA in ICT4D studies lacks a theory that provides a balance between Sen's functionings and capabilities. In order to fill this gap, we propose the theory of eParticipation as responsible for the expansion of several human capabilities and freedoms of individuals.

In this study, we considered the eParticipation field as shaped by Sæbø et al. [20] and Medaglia [13] combining the capability approach of Sen [23] and Nussbaum [17]. Although the capability approach is particularly difficult to operationalize in practice [27], we discovered some mechanisms in the eParticipation literature that could be seen as a way to operationalize it.

This paper starts off by reviewing the eParticipation literature, then we discuss the aspects of human development and the capability approach (CA). The relationship between eParticipation categories, CA and ICT4D is discussed in Section 5. Final remarks and possibilities for future research are presented in the last section.

\section{Electronic Participation}

According to Sæbø et al [20] eParticipation contextualization includes the expansion of transparency and people awareness of government activities and ICT-enabled public services. In addition to making information available, the purpose of eParticipation is to create an online ecosystem to support "citizen involvement in deliberation and decision-making processes" [20 p.403].

For better understanding those online participatory spaces, Medaglia [13] and Sæbø et al. [20] have designed a eParticipation framework defined by five categories: eParticipation activities (eVoting, online political discussion, online decision-making, eActivism, eConsultation, eCampaigning and ePetitioning) characterized as social activities; eParticipation effects (deliberative, democratic and civic engagement) which includes all outcomes, i.e., the impact of eParticipation activities; Contextual factors (underlying technologies, governmental organization, infrastructure, policy and legal issues), that are not part of eParticipation nature, but have a direct effect on these activities; eParticipation actors (citizens, politicians, government institutions and voluntary organizations), comprised of the main actors involved in eParticipation activities; eParticipation evaluations (transparency and openness, quantity, tone and style, demographics), concentrate on assessing and measuring eParticipation effects, activities and actors, focusing on transparency and openness issues. 
In this study, we used these five categories to analyze how eParticipation has the potential to increase individual capabilities.

The result of eParticipation activities, considering contextual factors, refers to the impact of these activities in terms of desirable and undesirable outcomes in order to achieve some kind of benefit sought through them [13] The main discussion in this study deals with the effects - viewed as capabilities - which can be chosen by individuals - eParticipation actors - and constitutes a fundamental aspect of Sen's capability approach theory. However, as Medaglia [13] remarks, there is a significant risk of public sphere fragmentation and polarization, as a result from the bad diffusion of Internet-based forms of political participation, what could jeopardize people participation in ICT4D context.

\section{Human development and the capability approach}

Human development is conceptually founded on the capability approach (CA), which aims to expand people's choices. Sen [23] argues that human development takes place through the expansion of capabilities that individuals consider important to have. The concept of agency -the capacity of individuals to act independently and make their own free choices - is intrinsically linked to the capability approach, since individuals are the agents of their own choices, of what they value. Nussbaum [17], who added on to Sen's concept, regards the capability approach as opportunities created by a combination of personal skills and influences from political, social and economic environments.

Along these lines, Sen [23] believes that well-being achievements should be measured in functionings, whereas well-being freedom is reflected by a person's capability set (a set of capabilities available to be chosen). Furthermore, "[...] the focus on agency will always transcend an analysis in terms of functionings and capabilities, and will take agency goals into account" [19 p.103].

Sen's reasoning is based on the evaluation of social change in terms of improvement to human life. His approach conceives of human life as a set of activities and ways of being called functionings. He relates the judgment of quality of life to the ability to perform these functionings. So, the capability approach is seen as a theoretical framework that demands the freedom to achieve well-being and agency and that can be understood in terms of people's capabilities [19,27].

Sen [23] does not specify a list of minimum basic capabilities for quality of life, but addresses the subject by stating that one cannot escape assessment of the problem when defining a class of functionings as important and others as not so important. According to him, in some welfare analyses a few functionings can be established, such as the ability to eat well, live well or partake of community life. Sen [21] argues that the first characteristic of well-being can be seen as a vector of functionings, that is, the set of functionings that a person achieves.

A complementary approach is contained in Nussbaum's ten central capabilities. She considers that these central capabilities are the bare minimum in a widely shared 
understanding of the task of governments. She also believes that these central capabilities can enable people to lead a dignified and minimally flourishing life and, consequently, are necessary for human development. Additionally, she focuses on a central question that can make the discussion more explicit: Which capabilities are the most important? The ten core capabilities defined by Nussbaum [17] are: (1) life, (2) physical health, (3) physical integrity, (4) senses, imagination and thought, (5) emotions, (6) reason, (7) affiliation, (8) other species, (9) play and (10) control over one's environment.

\section{Electronic Participation in the ICT for Development context}

On the one hand, Avgerou [2] acknowledges that research on the developmental potential and impact of ICT is multidisciplinary and involves Information Systems (IS), Human Computer Interaction (HCI), Communication and Development Studies [7]. Focusing on the development issue, Walsham et al. [26 p.317] believe that ICT can help improving socioeconomic conditions in developing countries. Walsham [26 p.89] elaborates on this idea affirming that "IS scholars and practitioners should be concerned with how to use ICT to help make a better world, where everybody has the opportunity and capability to use technologies to make better lives for themselves, their communities and the world in general".

On the other hand, Brown and Grant [4] pointed out the duality within the research body and suggested two distinct streams of research: studies focusing on (1) understanding technology "for development" (ICT4D) and (2) understanding technology "in developing" countries (ICTD). In turn, Heeks [8] identified several elements that comprise the disciplinary foundations for development informatics research, in addition to categorizing the theories for ICT4D research. In a complementary approach, Heeks [8 p.627] notes that "[...] infrastructure and access are only the starting point in understanding ICT's contribution to development; they are inputs whereas our real attention should be focused on outputs".

In an effort to link these two points of view, value chain based on the standard input-process-output model to create a sequence of linked ICT-for-development (ICT4D) resources and processes [8], which Heeks [7 p.627] divided into four domains: Readiness, Availability, Uptake and Impact.

For discussing eParticipation in the ICT4D context, thinking in Heeks [7] framework, besides guaranteeing technological infrastructure, participatory initiatives must take account citizens' capabilities and limitations to participate and to assess their degree of participation and their role in decision-making. We argue in the next sections that Capability Approach (CA) can be the theoretical lens through which we can better analyze the people's participation in ICT4D context.

\section{5 eParticipation,Capability Approach and ICT4D}

The pursuit to eradicate poverty and the realization of Sen's capability approach are accepted by Avgerou [2 p.2] as important research in ICTD studies. She states that 
"even if not explicitly acknowledged, every ICTD study makes specific assumptions about the way IT innovation happens in the context of developing countries".

In this sense, the study by Puri and Sahay [18] examines the relationship between participation, ICT use, and rural development processes. By reflecting about who defines the participation agenda in developing countries they identify that in many cases it is externally driven, but in some situations it is shared with communities/IS users, it is a community/user driven agenda, and in a few locations it moves towards empowerment, the agenda set by people. They also address what capabilities people need to be able to participate. established to elicit participation, and (e) the knowledge participants have about the problem domain.

Related to this this context, Puri and Sahay [18] pose the question: "How can local participatory processes be sustained and scaled up?" They search for elements in development theory and information system theory to answer this question. In both, the problems of scale and sustainability are crucial. They conclude that if the success of development is based on effective participation, then sustaining these projects over time requires a deeper institutionalization of participatory processes.

Another contemporary study, closely related to eParticipation in the ICTD context, was conducted by Kock and Gaskins [12]. They examined the relationships between Internet diffusion, voice and accountability, and government corruption. According to these authors, policy-makers in developing countries who desire to increase voice and accountability at the national level, and thus the degree to which their citizens participate in the country's governance, should strongly consider initiatives that broaden Internet access in their countries.

In the literature review, it is possible to note the degree of empowerment promoted by ICT access, enabling citizen participation in virtually any public service, not necessarily only in politics or government-related topics [24]. Zheng [27 p76] refers to the perspective of Avgerou [2] of the social embeddedness of IT innovation: "[...] even though ICT is perceived as commodities, it has to be considered in connection with the conversion factors and decision-making mechanisms when applied in the context of development". We bridge this gap by understanding the interplay between eParticipation categories and the central human capabilities of Nussbaum [17]. We contend that eParticipation addresses the expansion of several of these human capabilities through eParticipation activities and heightens the capabilities and freedom of individuals, making them more active in society.

To achieve the paper's objective, we have created a conceptual model that shows the relationship between eParticipation, capability approach and ICT4D. The purpose was to analyze the role of eParticipation increasing individual capabilities in the ICT4D context. We operationalize it by taking the concepts presented by Sæbø et al. [20] and Medaglia [13] work on ePartcipation field, combined to Sen [19] and Nussbaum [17] perspectives of capability approach and taking the ICT4D as context. We argue that eParticipation activities are resources provided by government to expand people's capability set (freedom), allowing them to achieve a functioning. 


\section{1 eParticipation activities versus central capabilities}

Nussbaum [17] stated that the task of government is to enable people to lead a dignified life, or, as Sen [19] presented in his work, to pursue life as a person of value. Through eParticipation activities, governments can provide a set of opportunities (or freedom) for people to choose from Sæbø et al. [23] and Medaglia [13] describe several eParticipation activities that could be considered as a set of expanded capabilities available to individuals, such as the capability to express one's self, vote and participate in communities, make decisions or be informed, resulting in functionings involving living and participating in groups, expressing one's own opinion, listening, being listened to and having access to information for the decision-making process. These activities represent some of the core capabilities necessary for human development, as mentioned by Nussbaum [17], especially to make political choices and enjoy freedom of expression. In this regard, it is possible to identify central capabilities that are expanded by eParticipation activities directly and indirectly.

The four central capabilities that are directly expanded by eParticipation activities are: (1) control over one's environment, (2) affiliation, (3) reason and (4) senses and imagination. This capability approach view of eParticipation is central to our work, that is, the role of eParticipation in the expansion of individual capabilities. We believe that every eParticipation activity is a new capability created or enhanced in a person. The use of ICT in participation activities increases the comprehensiveness of such activities. By using ICT, particularly the Internet, eParticipation activities can exploit the decision-making process, asking citizens to contribute in certain necessary decisions. Again, if we analyze this participation process from the angle of CA, it is evident that there are now more citizens involved in the overall process. In this sense, by taking a general political dimension, we suggest the Proposition 1: By providing eParticipation activities governments will enlarge people's opportunities for political participation, directly enhancing aspects as control over one's environment, affiliation, reason and senses and imagination.

Literature distinguishes between electronic machine voting (in a fixed place) and electronic distance voting (by using ICT from different locations). Sæbø et al. [20] have pointed out, in their review of literature, important issues related to eVoting, like security, trust and also concerns to bridging the digital divide. Additionally, Medaglia [13] remarks that the adoption of eVoting systems has the potential to positively affect democratic deliberation and citizen engagement in politics. Thereby, we suggest the Proposition 1A: By participating in eVoting activities people will be able to (a) have the right of political participationin the sense of control over one's environment (b) to be treated as a dignified being whose worth is equal to that of others in the sense of affiliation.

Sæbø et al. [20]'work highlights the increase of citizens' opportunities for agenda setting and policy making through the use of ICT. They also found some research that demonstrated that online participants are well-educated and already politically active. They also argued that the challenge is how to connect online political discourse to more traditional channels. On the other hand, Medaglia [13] emphasizes that the "ICT environments constitute spaces where participation and deliberation in the political 
discourse take place" [13 p.351] and several transformations are ongoing like, for instance, the emergence of new types of parties; an open-source based model of politics that revolves around the role of voters as co-producers of political discourse (e.g. blogs). Thereby, we suggest the Proposition 1B: By participating in online political discourse activities people will be able to engage in critical reflection about the planning of one's own life in the sense of Reason.

Both studies, Sæbø et al. [20] and Medaglia [13]'s, agree that online decisionmaking is focused on the direct link between participants and the political decisionmaking process. This category implies "... an explicit link with political decisionmaking through the use of ICT and is seen as a potential avenue for increasing political participation" [20 p.408]. However, Medaglia [13] points up that the majority of the studies investigated by them focus on platforms for specific decision-making purposes (e.g. parliamentary debates, participatory budgeting, collaborative drafting of policy documents and urban planning). Proposition 1C: By participating in online decision-making activities people will be able to participate effectively in political choices in the sense of control over one's environment.

According to Medaglia [13], the term eActivism refers to "all activities carried out by voluntary organizations, interest groups, and individuals to promote viewpoints and interests using ICT tools" [13 p.351]. Sæbø et al. [20] also call attention to the fact that such groups, organizations and individuals seek to influence the political process by using technological means to promote their interests. These authors are mainly concerned about understanding "to what extend such activities really increase the opportunities of citizens (rather than the activists themselves) to participate may be questioned" [20 p.409]. For example, in an eActivism activity, people can express themselves to others and engage in important discussions. One might ask: "Is eActivism the only way people can express themselves or engage in discussions?" The answer is no, but with eActivism people can expand their capability of activism, participate in many discussions at the same time and increase their voice. Thereby, we suggest the Proposition 1D: By participating in eActivism activities people will be able to (a) use one's mind in ways protected by guarantees of freedom of expression with respect to political speech in the sense of senses and imagination, (b) engage in various forms of social interaction in the sense of affiliation and (c) having the right of political participation, free speech and freedom of association in the sense of control over one's environment.

Medaglia [13] summarizes the concept of eConsultation as follows: "eConsultation is an activity of providing ICT-enabled feedback mechanisms from citizens to governments and public agencies, usually initiated by the latter" [13 p.352] Sæbø et al. [20] highlight that eConsultation focuses on how to increase input from the different stakeholders in government (from citizens, companies or societal groups). The main point discussed in the literature investigated by them is related to how to increase the level of participation and how to include new societal groups. Another important issue is related to transparency as well as the design of the eConsulation services. In the same way, ePetitions refers to a tool through which citizens could influence decision makers' agendas by proposing themes or decisions to be discussed. In ePetition systems, citizens sign a petition online proposing an issue for consideration by the politi- 
cal system [20 p.410] Considering that both activities corroborate with a participatory democracy, we suggest the Proposition 1E: By participating in eConsultation and ePetition activities people will be able to (a) participate effectively in political choices in the sense of control over one's environment, (b) live with and in relation to others, to recognize and show concern for other human beings, to engage in various forms of social interaction; and (c) imagine the situation of another and have compassion for that situation; having the capability for both justice and friendship in the sense of affiliation.

Medaglia [13] and Sæbø et al. [20]'s research has not found studies focusing on eCampaigning. However, Medaglia [13] recognized that the use of digital tools with participatory objectives by politicians in the context of electioneering is widespread and the use of social media is "... paradoxically found to reflect the one-way communication structures of traditional political campaigning, and not to foster citizen involvement in decision-making" [13 p.352] In this sense, it might foster transparency, which is closely related to eParticipation, as a way to increase citizens' trust and creating new possibilities of public interaction and participation [15]. Thereby, we suggest the Proposition 1F: By participating in eCampaigning activities people will be able to (a) imagine, think and reason in an informed way in the sense of senses and imagination and (b) form a conception of the good and to engage in critical reflection in the sense of reason.

The central capabilities that are indirectly expanded by eParticipation activities are: (1) life, (2) physical health, (3) physical integrity, (4) other species, (5) play and (6) emotions. By taking the capability approach, Kleine [11] states that very often ICTbased resources might represent tools used by individuals to enhance capabilities besides a capability itself. Considering development as the expansion of the capacities of human beings to lead lives they value, ICT should be seen as a means to achieve this objective in the development process, conditioned to a set of conversion factors [27]. Helbig et al. [9] emphasizes the lack of attention on citizens' needs and questions if users actually want, or could they use, what government were given. In this way, we suggest the Proposition 2: The engagement in eParticipation activities might represent a mean that allow people to express their needs and expectations to achieve what is valued by them (indirectly enhancing aspects as life, physical health, physical integrity, other species, play and emotions).

\subsection{Contextual factors versus internal capabilities with external opportunities}

Although ICT is a key factor for boosting citizen participation, the technology is not available to the entire population. In this respect, Helbig et al. [9] argue that simply dividing people into two groups - those who have or do not have ICT access - does not encompass all the difficulties posed by digital exclusion, since problems of access and use are also issues that need to be discussed. Before ICT can become a tool for expanding citizen participation that is available to all, governments must address structural problems, such as lack of electricity, Internet costs and training for lowincome citizens, among others. Contextual factors, as pointed out by Sæbø et al. [20] and Medaglia [13], constitute resources for achieving increased capabilities. Howev- 
er, if ICT access is not possible, this should be viewed as a deprivation of liberty, a reduction in capabilities and inequality of access. Therefore, contextual factors are resources that influence the set of available capabilities. Thus, we suggest the Proposition 3: The expansion of individual capabilities through eParticipation activities is conditioned by contextual factors.

Kleine and Unwin [11] identified many factors that influence people's choices. Some of them, as previously discussed in the realm of eParticipation and ICT4D, are material resources, such as tools, equipment and hardware (computers). If a person does not have any ICT device, or Internet access, or even electricity, participation in electronic activities will be restricted. The author lists human resources as educational and skills as potential influencers of people's capability to partake of a certain opportunity. The inequality created between those who have access to technology and those who do not is, in many cases, driven by inequality of education. If, for example, we recognize that even a person with computer access and basic computer skills may not have the ability to understand a subject in an eVoting activity, there will still be restrictions on the extensive use of this mechanism. In sum, the individual capabilities of people with limited access to eParticipation tools (e.g., Internet) are consequently reduced. Furthermore, even individuals with ICT access may have difficulties developing their knowledge, skills and confidence in the use of ICT. Thereby, we suggest the Proposition 3A: The digital divide might restrict people's engagement in eParticipation activities constraining the possibility for people to participate effectively in political choices that govern one's life; having the right of political participation, free speech and freedom of association.

Nussbaum [17] introduces the concept of internal preparedness with external opportunity. According to her, "[...] a society might do well at producing internal capabilities but might cut off the avenues through which people actually have the opportunity to function in accordance with those capabilities". For example, a person who has all the internal capabilities to vote, i.e., political knowledge, a high enough educational level to understand the different proposals, might be prevented from voting in a certain political regime. Therefore, eParticipation activities can promote or expand freedom (external opportunities) to leverage this person's internal capability. One clear example is eActivism, which leverages the internal capability to criticize the government. Another example is if a person with a disability or heath issue wants to join in on any government participation activity, he or she can now do so, from literally anywhere, at home or even in a hospital, instead of going to a central location (government office). In that way, we suggest the Proposition 3B: The degree of empowerment promoted by ICT access might increase people's engagement in eParticipation activities enlarging the possibility for people to participate effectively in political choices that govern one's life; having the right of political participation, free speech and freedom of association. 


\section{3 eParticipation effects, actors and evaluation versus individual realized functionings}

Functionings are ways through which well-being achievements can be evaluated. A personal achievement is a set of functionings that demonstrates human well-being. In this sense, agency - the ability of individuals to make their own free choices - can be seen in eParticipation effects such as civic engagement level, an increased democratic and deliberative level or other social impacts, like community empowerment choice and voice. These effects, as eParticipation outcomes, should be thoughtfully heeded in public policy development.

The opportunity to participate in democratic decisions is a capability provided by government. People's choice to effectively use this capability and participate in a deliberative forum is a functioning. Agency and choice are fundamental issues in this case. For instance, a person chooses to engage or participate in a specific online activity. Sen [22] argues that agency is the ability to act on behalf of what a person values. In the eParticipation context, we use agency to choose in which activities to participate (e.g.: eVoting, eDeliberation and/or eActivism). At this point we can consider the role of governments in eParticipation, specifically, as providing activities for use by citizens. This means the realization of capabilities, at the end the functioning proposed by Sen [22] Thus, we suggest the Proposition 4: The individual achievement of functionings, through eParticipation activities, is conditioned by individual's choice in engaging on these activities.

In eParticipation theory, actors are individuals who are engaged in eParticipation effects, or using CA vocabulary, the functioning. Bearing in mind that the term 'capability' refers to environmental opportunities and individual abilities, actors are those who are directly involved in participation through ICT access: citizens, politicians and government institutions. For instance, whoever is behind the computer (or any other device) taking part in an eConsultation or any other eParticipation activity is an individual. By taking a supply and demand perspective of eGovernment, it is possible to verify the phenomena in terms of eParticipation actors. The supply side focuses on "initiatives that create electronic services and, in many cases, opportunities for participation from citizens, businesses, and other stakeholders". Considering the demand side the focus is on "how different social groups try to take advantage of these services and of the other uses of information and communication technologies within society" [13 p.93].

Using the capabilities available, the individual achievement of functionings which is a result of personal choice - can be evaluated by the realized functionings. The main mechanism in eParticipation that can be identified is transparency and openness. Openness makes it possible for people to get involved in the processes of government and create value for both [1]. As more government data is available, it will be easier for citizens to find information about government activities, being able to complain and communicate their opinion, representing an increase in their interest in actively participate in the government process. 


\section{$6 \quad$ Final Remarks}

The objective of this paper was to understand how eParticipation could contribute to increase individual capabilities in an ICT4D context. We started off with the premise that eParticipation can increase different individual capabilities. Moreover, eParticipation in its various forms of social and political engagement is undoubtedly a breakthrough toward increased individual freedom. We know that technology has the power to engage individuals but, at the same time, it can marginalize those who do not have ICT access or the skills to take advantage of it. Indeed, public policy should be created to benefit all citizens, wherever they live.

In this study, we sought to contribute by proposing to fill the gap identified by Zheng [27] that CA requires additional social theories to evaluate and analyze the ICT4D context. For this reason, we focused on eParticipation to analyze some of its features using Nussbaum's core capabilities and Sen's CA. As a result, we have, to a certain extent, developed a proposal that enables us to implement and comprehend, in a concrete way, the relationship between eParticipation categoriesand CA (see Figure 1). We believe that this theoretical contribution could provide support to good management in public affairs.

Nevertheless, this paper is a proposal that could serve to launch a new study. For instance, a case study could be carried out to highlight the insights gained from the relationship between eParticipation categories and CA for public policy-making in the ICT4D context. Other studies could also include institutional analysis and CA in ICT4D [3] from an eParticipation perspective, or ones that focus on Smart Cities, more specifically on the way they represent innovation in management and policy as well as technology [16] and public value [5]. A helpful theoretical approach could be developed to investigate Smart Cities and help governments prevent social, political and organizational problems.

\section{References}

[1] Agrawal, D., Kettinger, W., Zhang, C.: The Openness Challenge: Why Some Cities take It On and Others Don't. IN: Proceedings of the 20th Americas Conference on Information Systems (AMCIS 2014), Savannah, Georgia, USA, (2014).

[2] Avgerou, C.:Discourses on ICT and Development. Information Technologies and International Development 6(3), 1-18 (2010).

[3] Bass, J.M, Nicholson, B., Subrahmanian, E.: A Framework Using Institutional Analysis and the Capability Approach in ICT4D. Information Technologies \& International Development 9(1), 19-35 (2013).

[4] Brown, A. E., Grant, G. G.:Highlighting the duality of the ICT and development research agenda. Information Technology for Development 16(2), 96-111(2010).

[5] Harrison, T. M., Guerrero, S., Burke, G. B., Cook, M., Cresswell, A., Helbig, N., Pardo, T.: Open government and e-government: Democratic challenges from a public value perspectiveL. Information Polity 17(2), 83-97(2012).

[6] Heeks, R.: Theorizing ICT4D research. Information Technologies and International Development, 3(3), 1-4(2007). 
[7] Heeks, R.: Do information and communication technologies (ICTs) contribute to development?, Journal of International Development, 22(5), 625-640(2010).

[8] Heeks, R., Molla, A.: Impact Assessment of ICT-for-Development Projects: A Compendium of Approaches, Development Informatics Working Paper No. 36, University of Manchester, UK. (2009).

[9] Helbig, N., Ramón Gil-García, J., Ferro, E.:Understanding the complexity of electronic government: Implications from the digital divide literature. Government Information Quarterly, 26(1), 89-97 (2009).

[10] Kleine, D.:Technologies of Choice: ICTs, development and the capabilities approach. Cambridge: MIT Press(2013).

[11] Kleine, D., Unwin, T.:Technological Revolution, Evolution and New Dependencies: what's new about ict4d? Third World Quarterly, 30(5), 1045-1067.(2009).

[12] Kock, N., Gaskins, L.: The Mediating Role of Voice and Accountability in the Relationship Between Internet Diffusion and Government Corruption in Latin America and SubSaharan Africa, Information Technology for Development, 20(1), 23-43(2014).

[13] Medaglia, R.: eParticipation research: Moving characterization forward (2006-2011). Government Information Quarterly, 29(3), 346-360(2012).

[14] Madon, S.:Evaluating the developmental impact of e-governance initiatives: an exploratory framework. Electronic Journal on Information Systems in Developing Countries. 20(5), 1-13(2004)

[15] Miranda, P. R. M., Cunha, M.A., Pugas-Filho, J. M.: eParticipation in Smart Cities of Developing Countries: Research-Based Practical Recommendations. In: J. Ramon GilGarcia; Theresa Pardo; Taewoo Nam. (Org.). Smarter as the New Urban Agenda. 1ed.Switzerland: Springer International Publishing, v. 1, 315-332(2016).

[16] Nam, T., Pardo, T. A.: Smart city as urban innovation: Focusing on management, policy, and context. In: Proceedings of the $5^{\text {th }}$ International Conference on Theory and Practice of Electronic Governance, pp. 185-194, $\operatorname{ACM}(2011$, September).

[17] Nussbaum, M. C.:Creating capabilities. The Human Development Approach. Cambridge, Harvard University Press(2011).

[18] Puri, S. K., Sahay, S.: Role of ICTs in participatory development: An Indian experience. Information Technology for Development, 13(2), 133-160(2007).

[19] Robeyns, I.: The capability approach: a theoretical survey. Journal of Human Development, 6(1), 93-117(2005).

[20] Sæbø, Ø., Rose, J., Skiftenes Flak, L.:The shape of eParticipation: Characterizing an emerging research area. Government Information Quarterly, 25(3), 400-428 (2008).

[21] Sen, A.: Well-Being, Agency and Freedom: The Dewey Lectures. Journal of Philosophy, 82(4), 169-221(1985).

[22] Sen, A.:Development as Capability Expansion. Journal of Development Planning, 19, 41-58 (1989).

[23] Sen, A.: Development as Freedom. Oxford University Press(1999).

[24] Susha, I.,Grönlund, A.:eParticipation research: Systematizing the field. Government Information Quarterly, 29(3), 373-382(2012).

[25] Walsham, G., Robey, D., Sahay, S.:Foreword: Special issue on information systems in developing countries. MIS Quarterly, 31(2), 317-326(2007).

[26] Walsham, G.:Are we making a better world with ICTs? Reflections on a future agenda for the IS field. Journal of Information Technology, 27(2), 87-93(2012).

[27] Zheng, Y.: Different spaces for e-development: What can we learn from the capability approach? Information Technology for Development, 15(2), 66-82(2009). 